Anales de Historia del Arte ISSN: 0214-6452

\title{
Celebrar el encuentro entre el arte y la sociedad. Una conversación con
} Miguel Zugaza

Eva Fernández Del Campo ${ }^{1}$

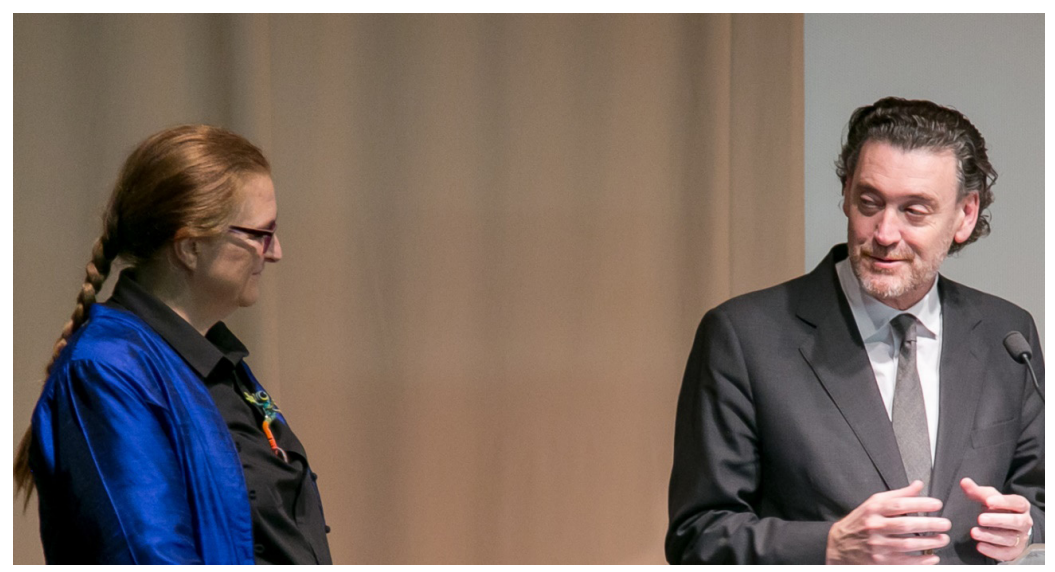

Bilbao está lluvioso y gris, pero imponente, la mañana del 24 de enero de 2019 en que charlo con Miguel Zugaza en el Museo de Bellas Artes, la institución que él ha vuelto a dirigir tras quince años al frente del Museo del Prado. Se le ve feliz y relajado, aunque pronto entiendo que eso que parecía una especie de retiro a una vida apacible y algo más sosegada de lo que era la actividad madrileña no es tal. Nada más llegar al Museo el nuevo director ha emprendido la tarea de reorganizar de forma drástica su museografía y se enfrenta, además, al proyecto de una nueva ampliación del edificio que lo haga volcarse hacia la ría, totalmente transformada en los últimos años.

Mientras recorremos juntos el museo y me explica el nuevo diseño de las salas el Zugaza tímido se transforma en un entusiasta a quien le brillan los ojos al hablar de sus obras preferidas, de cómo han ido encontrado su lugar y compañía en estas salas totalmente renovadas, de aspecto mucho más amplio y moderno que las de antes, y que se han convertido en páginas de un diccionario artístico ideado por el escritor Kirmen Uribe.

Esa mezcla de serenidad y pasión, entiendo ahora, es la que le ha permitido durante tantos años llevar la difícil y pesada carga de la dirección del Museo de El Prado consiguiendo mantener el tipo frente a políticos de distintos partidos, atravesando la grave crisis económica que azotó el país desde 2007 y coordinando al enorme

Orcid 0000-0002-4125-0191 Directora de Anales de Historia del Arte 
equipo de profesionales que trabajan en la pinacoteca. También sé que Miguel Zugaza es un gran diplomático y que va a contestar a mis preguntas educadamente sin dejarse sorprender en nada. Es todo amabilidad y tan solo se percibe muy sutilmente el constante dolor de espalda que le aqueja en un levísimo gesto en el entrecejo que se disipa siempre con una sonrisa afable.

\section{E.F.C. Has sido el director más joven del Museo del Prado y al mismo tiempo el más longevo. Quince años dirigiendo una de las pinacotecas más importantes del mundo. ¿Qué te propusiste al llegar?}

De la historia reciente del museo creo que ostento ese récord. En la historia bicentenaria del Prado, tengo que señalar que Federico Madrazo fue director, por primera vez, más joven que yo, y Álvarez Sotomayor fue mucho más longevo en el cargo. En cualquier caso, la historia del Museo del Prado es una acumulación de esfuerzo de los sucesivos directores. Muchas veces he pensado que no hemos hecho otra cosa que culminar proyectos ideados por Pérez Sánchez o nuestro querido Paco Calvo, dos de los directores más inspirados e inspiradores que ha tenido el Prado.

\section{E.F.C. ¿Harías algo de otra manera si empezases ahora a dirigirlo?}

Hoy el museo es muy diferente, y el mundo, no digamos. El museo de hoy tiene la responsabilidad de culminar el proyecto de ampliación con la incorporación del Salón de Reinos, que significa dar la forma definitiva al magnífico Campus del Prado. A partir de aquí, dedicarse a hacer un buen trabajo científico y de conservación, que beneficie el valor y la experiencia de la colección delante de una creciente audiencia. Para ello necesita el apoyo del gobierno y de las instituciones públicas regionales y locales. No pueden dejar pasar la gran oportunidad de dar ese salto final a la dimensión del museo. Nadie lo entendería.

E.F.C. Se ha hablado de ti como de un director de consenso. Has estado bajo los gobiernos del PP y del PSOE, y tu gestión ha sido muy elogiada. Te has enfrentado a tareas tan difíciles como la ampliación o el cambio de modelo de gestión. ¿Un director de museo es más un gestor que un investigador?

Yo era más gestor que investigador, pero era un historiador del arte y las prioridades estaban siempre donde tenían que estar: en la creencia de que no podíamos mejorar el Prado sin mejorar nuestra autoridad intelectual y técnica. Sin esa apuesta, las exposiciones y actividades serían irrelevantes y dejarían de tener interés para los visitantes. La visión organizativa y financiera es muy importante, pero sin traicionar la verdadera misión pública del museo, que, desde su fundación, no es otra que la de conservar material e intelectualmente una maravillosa colección para ponerla al servicio de la educación y el deleite de la sociedad. Tan sencillo y tan complejo a la vez 


\section{E.F.C. ¿Qué relación crees que debe tener la Universidad con el Museo?}

Deberían trabajar a piñón partido, pero desgraciadamente no lo hacen. Hace unos años elaboramos un estudio de las tesis doctorales en Historia del arte que se presentaban en las principales universidades españolas, analizando en qué proporción los temas atendían directa o indirectamente aspectos de las colecciones del Prado. El resultado fue una auténtica decepción. Alcanzaba escasamente el 1\%. Creo que las dos instituciones debemos hacer una severa autocrítica.

\section{E.F.C. En tu formación y en tu manera de ver el arte, habrá habido profesores que te han marcado.}

Muchos, y de esa Universidad, unos cuantos. Tuve la suerte, con mis compañeros, de disfrutar de los últimos años de docencia de una generación como Julián Gállego y Antonio Bonet Correa, y al mismo tiempo del magisterio de la generación de Paco Calvo y Ángel González. Viniendo de Deusto, me correspondía estudiar en la Autónoma, pero hice una solicitud para hacer la especialidad con este claustro en la Complutense.

E.F.C. ¿Qué papel tiene el museo en la sociedad actual?, ¿ha cambiado?, ¿y qué papel debe jugar ahora? Da la sensación de que los museos están sobre explotados, saturados de personas que, en realidad, no contemplan las obras, $y$ también da la sensación de que los jóvenes no van a los museos.

Los museos no han cambiado. Lo que cambia es la sociedad y sus hábitos culturales. Creo que debemos felicitarnos por el interés que manifiesta la sociedad por el arte y los museos en la actualidad. No ha sido fácil llegar a celebrar ese encuentro. En cualquier caso, los museos masificados son muy pocos. La mayor parte de los museos del mundo son muy poco visitados. El Prado, afortunadamente, todavía no lo está, y en este sentido puede demostrar que se puede hacer razonable el entusiasmo de la sociedad por el arte con la visita al museo.

E.F.C. Las tarifas no parecen favorecer mucho que los jóvenes y la gente corriente acuda a los museos. Sin embargo, cada vez más, el éxito de los museos y de las exposiciones se mide por el número de visitantes que hacen caja. ¿Qué opinas de esto?

El número de visitantes no es el indicador de éxito de un museo y menos la motivación de su programa de exposiciones. Creo que existe un gran desconocimiento sobre las opciones de visita de un museo como el Prado. Los jóvenes hasta los 25 años entran gratis. Además, todos los días, las dos últimas horas de entrada al museo son gratuitas para todo el público. Más del 50\% de los visitantes anuales al Prado no paga la entrada. 
cuestión del museo como un lugar abierto a la ciudadanía, donde deben suceder cosas. Hay quien propone, sin embargo, que el museo debe ser algo más próximo a un santuario. Estoy acordándome de Ángel González, cuando decía, con su ironía de siempre, que un director de museo debía solamente procurar que en el museo se limpiase el polvo y que no pasase nada más. ¿Qué opinas de esa disyuntiva?, ¿se plantea solo entre el arte antiguo y el arte contemporáneo?, ¿es un problema de punto de vista de los conservadores?, ¿de los discursos museográficos?

Siento contradecir a mis profesores, pero es necesario recordar que el museo es una institución pública inventada por los ilustrados y puesta a prueba en los tiempos de la revolución política y social en el tránsito entre el Antiguo Régimen y nuestra Edad Contemporánea. Cuando el Louvre era el Palacio del Rey de Francia, seguramente con pasar el polvo era más que suficiente, pero convertido por Napoleón en un museo, ya no puede renunciar a su vocación pública. A muchos colegas, historiadores y conservadores de museos les fascinaría que el museo volviera a verse como un palacio. No es mi caso. Creo que, poniendo en contacto el arte con las personas, se cumple la misión del museo. Con nuestro trabajo debemos tratar de convertir esa experiencia en emocionante y memorable.

E.F.C. ¿Qué tiene que suceder para que haya una mujer directora del Museo del Prado?

En la dirección o al frente del Patronato del museo, ¿por qué no? Sería un signo de triunfo del cambio que se está operando con éxito en relación con la igualdad en nuestra sociedad.

E.F.C. ¿Qué pasa con las mujeres artistas? ¿Por qué el Prado y el resto de los grandes museos, en general, no se han preocupado de rescatar las figuras de las mujeres artistas?

No pasa más que, a lo largo de la historia del arte occidental, las trayectorias de las mujeres artistas no han sido tan atendidas como las de sus contemporáneos varones. Esto explica la falta de ejemplos de muchas de ellas en los museos y colecciones públicas. Eso está cambiando en los museos actuales. El Museo de Bellas Artes de Bilbao, por ejemplo, dentro de su modestia, ha aprobado la creación de un fondo específico para adquisiciones de obras de mujeres artistas.

E.F.C. En el Museo del Prado existe la antigua discusión teórica sobre si la colección debe exponerse respondiendo a su condición de colección de arte español o a su carácter de Colección Real, o hay incluso voces que hablan de la necesidad de hacer una museografía más "innovadora" en la que se confronten y se hagan dialogar obras distintas o distintos periodos. ¿Cuál es tu opinión?

Creo sinceramente que no hay una sola forma de contar la historia del arte y menos las historias que contiene el arte. Los responsables de los museos debemos intentar 
abrir nuevas narrativas que permitan aproximaciones diferentes a las colecciones. Las exposiciones temporales te permiten este tipo de lecturas transversales como la que se hizo con La belleza encerrada, reuniendo las obras de dimensiones más reducidas del museo. Para los propios conservadores fue una oportunidad de valorar la colección del Prado. En cualquier caso, se puede ser más atrevido en museos medianos como el de Bilbao. Hace unos meses hemos presentado la colección como un alfabeto, en un orden temático no cronológico o por escuelas. El público que conoce la colección la está disfrutando otra vez.

\section{E.F.C. Sin contar el Museo del Prado o el Museo de Bellas Artes de Bilbao, ¿cuál es tu museo ideal? ¿Por qué?}

Claramente al que solo le tuviéramos que quitar el polvo para que el arte se expresara con todo su poder de fascinación. 